\title{
CARTOGRAFIA HISTÓRICA E GEOPROCESSAMENTO: O EXEMPLO DOS MAPAS DOS PADRES MATEMÁTICOS, DE 1734, E DO CÁLCULO DE RENDIMENTOS GERAIS DO BISPADO DE MARIANA, DE 1752
}

\section{José Flávio Morais Castro ${ }^{1}$}

Resumo: Os mapas históricos vem sendo objeto de interesse especial de pesquisadores de variadas áreas, pela sua importância como registro de valores culturais da sociedade no espaço e no tempo. Este trabalho tem por objetivo analisar as interfaces entre a Cartografia Histórica e o geoprocessamento, adotando-se, como exemplo, o georreferenciamento e a vetorização dos mapas da Capitania de Minas Gerais elaborados pelos padres matemáticos Diogo Soares e Domingos Capassi, em 1734. Pretende-se, também, representar o cálculo de rendimentos gerais do Bispado de Mariana, de 1752, por meio de mapas temáticos. Propõese um roteiro metodológico de utilização do geoprocessamento em informações históricas, fundamentado nos princípios da "Semiologia Gráfica" para o tratamento da informação espacial.

Palavras-chave: Cartografia Histórica; Geoprocessamento, Semiologia Gráfica, Padres Matemáticos, Bispado de Mariana.

\begin{abstract}
The historical maps has been the subject of special interest to researchers in a variety of areas, due to its importance as a record of the cultural values of the society in space and time. This work aims to analyze the interfaces between the Historical Cartography and GIS, adopting, with example, the georeferencing and vectorization of maps of the Captaincy of Minas Gerais developed by mathematicians priests Diogo Soares and Domingos Capassi in 1734. It is intended to also represent the calculation of general revenues of the Bishopric of Mariana, 1752, through thematic maps. We propose a methodological for use of GIS in historical information, based on the principles of "Graphic Semiology" for the treatment of spatial information.
\end{abstract}

Keywords: Historical Cartography, GIS, Graphic Semiology, Mathematical Priests, Bishopric of Mariana.

\section{INTRODUÇÃO}

O geoprocessamento de mapas históricos é um recurso sofisticado para as pesquisas em Cartografia Histórica, História da Cartografia, Geografia Histórica e áreas afins. O uso das técnicas de geoprocessamento em mapas históricos tem se mostrado eficiente no resgate

\footnotetext{
${ }^{1}$ Professor Adjunto IV do Programa de Pós-Graduação em Geografia - Tratamento da Informação Espacial da PUC Minas: E-mail: joseflavio@pucminas.br
} 
de importante patrimônio cultural da sociedade, evidenciando um riquíssimo instrumento de pesquisa e um poderoso instrumento didático-pedagógico.

Os mapas da Capitania de Minas Gerais dos séculos XVIII e XIX vêm sendo georreferenciados e vetorizados, no ARC GIS ${ }^{\oplus}$, por meio da geração de banco de dados, cujos trabalhos vêm produzindo resultados em projetos de pesquisas de iniciação científica, de dissertação de mestrado e de tese de doutorado, por exemplo, com a técnica dos croquis interpretativos: os "mapas exaustivos" e a "coleção de mapas" (CASTRO et al., 2006; CARVALHO e CASTRO, 2009 e 2010); com a análise cartométrica (CAMARGOS e CASTRO, 2010; CAMARGOS, 2012; CASTRO, 2013); com as comunidades quilombolas (SILVA FILHO, AMORIM FILHO e CASTRO, 2011; SILVA FILHO, 2011); e, com as viagens dos naturalistas (DAIAN, 2011; CASTRO, 2012). Este trabalho tem por objetivo analisar as interfaces entre a Cartografia Histórica e o geoprocessamento, adotando-se, como exemplo, o georreferenciamento e a vetorização dos mapas da Capitania de Minas Gerais elaborados pelos padres matemáticos em 1734. Pretende-se, também, representar o cálculo de rendimentos gerais do Bispado de Mariana, em 1752, por meio de mapas temáticos. Em ambas aplicações, foram utilizados recursos de representação gráfica da "Semiologia Gráfica" (BERTIN, 1973).

No século XVIII, os padres matemáticos Diogo Soares e Domingos Capassi foram pioneiros no mapeamento do interior do Brasil, especialmente, nos aspectos físicos e naturais da região mineradora da Capitania de Minas Gerais.

As pesquisas em Cartografia Histórica evoluíram qualitativamente, principalmente a partir de 1930, quando surgiram publicações especializadas, especialmente na revista Imago Mundi, e com a emergência da cartografia como disciplina acadêmica.

Segundo Gomes (2004, p. 69), o geógrafo inglês J. Brian Harley identificou 1982, três sinais de mudanças na cartografia (HARLEY, 1990; 1991): o interesse no significado das palavras mapa e cartografia; a abordagem dos mapas como artefatos e a ênfase nos processos técnicos de sua produção; e, a abordagem dos mapas antigos como meio de comunicação. 
Um dos objetos de estudos da cartografia histórica são as técnicas cartográficas empregadas no mapa histórico, cuja multiplicidade de linguagens gráficas adotadas tem sido objeto de análise da história, da geografia, da arquitetura, da sociologia, da arqueologia, entre outras áreas.

No Brasil, as pesquisas sobre Cartografia Histórica assumiram um novo ritmo na década de 1970, com as publicações da Editora Itatiaia e da Editora da Universidade de São Paulo, por exemplo, sobre as viagens de Auguste De Saint-Hilaire (SAINT-HILAIRE, 1974a, 1974b, 1975), com os estudos de Raimundo José da Cunha Matos (MATOS, 1981) e de Diogo de Vasconcelos (VASCONCELOS, 1999), e com o "Dicionário Histórico-Geográfico de Minas Gerais", cuja primeira edição foi publicada em 1968 (BARBOSA, 1995).

Na década de 1990, principalmente com os estudos da Fundação João Pinheiro, houve uma iniciativa em resgatar a memória e a historiografia de Minas Gerais por meio da publicação da Coleção Mineiriana em 1993, constituída por edições de manuscritos, de tradução de textos, de mapas históricos, entre outras obras clássicas e raras da historiografia mineira.

Uma das primeiras obras publicadas foi a "Geografia histórica da Capitania de Minas Gerais. Descrição geográfica, topográfica, histórica e política da Capitania de Minas Gerais. Memória Histórica da Capitania de Minas Gerais" (ROCHA 1995), de autoria de José Joaquim da Rocha, elaborada em 1778, que apresenta textos e mapas da capitania e das comarcas. Outra contribuição importante foi a publicação "As denominações urbanas de Minas Gerais: cidade e vilas mineiras com estudo toponímico e da categoria administrativa" (IGA e ALEMG, 1993 e 1997), fonte para inúmeras pesquisas, principalmente aquelas ligadas à atualização de topônimo.

Em 1997, foi publicado o "Tratado de geografia descritiva especial da província de Minas Gerais" (SILVA, 1997). Em 1998, foram resgatadas as pesquisas de Halfeld e Tschudi (1998) e publicado o mapa histórico "Karte Der Brasilianische Provinz Minas Geraes", datado de 1855. Ainda no ano de 1998, foram publicadas: "Fontes primárias para a História de Minas Gerais em Portugal" (BOSCHI, 1998a), "Inventário dos manuscritos avulsos relativos a Minas Gerais existentes no Arquivo Histórico Ultramarino (Lisboa)" - (BOSCHI, 1998b), "O ouro em Minas Gerais" (FERRAND, 1998) e "Resgate bibliográfico de Minas Gerais" (ÁVILA, 1998).

Em 1999, foi publicada a coleção das notícias dos primeiros descobrimentos das minas na América, elaborada por Caetano Costa Matoso em 1749 (CÓDICE COSTA MATOSO, 1999). 
Nos anos 2000, foram publicados os diários das expedições de Wilhelm Ludwig von Eschwege (ESCHWEGE, 1996, 2000 e 2002).

A partir destas publicações surgiram no Brasil, nos anos 2000, grupos de pesquisa em universidades e em instituições públicas (museus e bibliotecas) que produziram variadas exposições de mapas históricos, organização de eventos científicos, criação de museus, publicações de livros (COSTA et al., 2002; COSTA, 2004; COSTA, 2005; COSTA, 2007; LAGO, 2009; entre outros), artigos em periódicos especializados e arquivos digitais de Cartografia Histórica na internet, por exemplo:

\section{Periódicos:}

$\checkmark$ Anais do Museu Paulista: História e Cultura Material.

$\checkmark$ Terra Brasilis.

$\checkmark$ Revista do Instituto Histórico e Geográfico do Rio Grande do Sul.

\section{Biblioteca virtual:}

$\checkmark$ Biblioteca Virtual de Cartografia Histórica do século XVI ao XVIII - Fundação Biblioteca Nacional. http://www.bndigital.bn.br/projetos.htm

$\checkmark$ Biblioteca Digital de Cartografia Histórica. www.mapashistoricos.usp.br

$\checkmark$ Centro de Referência em Cartografia Histórica. www.ufmg.br/rededemuseus/crch

$\checkmark$ Atlas Digital da América Lusa. http://lhs.unb.br/biblioatlas/Inicio

$\checkmark$ Atlas Histórico da Bahia Colonial.

$\checkmark$ http://www2.uefs.br/atlashistorico/agradecimentos.html

\section{Exposição:}

$\checkmark$ O Tesouro dos Mapas - Instituto Cultural Banco Santos - Palácio das Artes, Belo Horizonte, 2004.

$\checkmark$ Cartografia Histórica das Minas às Gerais - Secretaria de Estado de Educação de Minas Gerais - Centro de Referência em Cartografia Histórica (CRCH/UFMG) - Beo Horizonte, 2005.

$\checkmark$ A Arte nos Mapas na Casa Fiat de Cultura: uma viagem pelos quatro cantos do mundo - Belo Horizonte, 2008.

$\checkmark$ Coleção Brasiliana Itaú - Palácio das Artes, Belo Horizonte, 2010. 


\section{Laboratório:}

$\checkmark$ Laboratório de Cartografia do Programa de Pós-Graduação em Geografia Tratamento da Informação Espacial da PUC Minas.

$\checkmark$ Laboratório de Estudos de Cartografia Histórica (LECH) - Departamento de História (FFLCH - USP).

\section{Eventos:}

$\checkmark$ Cartografia Histórica, Museus e Conhecimento Escolar: Seminários às quintas Secretaria de Estado de Educação de Minas Gerais - Centro de Referência em Cartografia Histórica (CRCH/UFMG).

$\checkmark$ 4은 Simpósio Iberoamericano de História da Cartografia - BNP Lisboa - 2012.

$\checkmark$ I Simpósio Brasileiro de Cartografia Histórica - Paraty - 2011

$\checkmark$ Simpósio Luso-Brasileiro de Cartografia Histórica (Rio de Janeiro, 2005; Lisboa, 2007; Ouro Preto, 2009; Porto, 2011; Petrópolis, 2013).

$\checkmark$ XXIV Congresso Brasileiro de Cartografia - Aracaju - 2010.

$\checkmark$ 3은 Simpósio Iberoamericano de História da Cartografia - USP - 2010.

$\checkmark$ XXIII Congresso Brasileiro de Cartografia - Sociedade Brasileira de Cartografia - Rio de Janeiro, 2007.

Na Europa, principalmente em Portugal e na Espanha, mapas históricos vem sendo inventariados, catalogados e digitalizados em arquivos virtuais, por exemplo:

$\checkmark$ Projecto SIDCARTA do Exército Português. http://www.exercito.pt/bibliopac

$\checkmark$ A Cartografia do Brasil nas coleções da Biblioteca Nacional http://www.purl.pt/103

$\checkmark$ Biblioteca Nacional Digital. http://www.bn.pt

$\checkmark$ Instituto Geográfico Português. http://www.igeo.pt

$\checkmark$ Atlas de Cartografia Histórica. http://www.fcsh.unl.pt/atlas/

$\checkmark$ Biblioteca Nacional de Espanha. http://www.bne.es

$\checkmark$ Museo Naval de Madrid. http://www.armada.mde.es/museonaval

$\checkmark$ Catálogo General de Publicaciones Oficiales. http://www.060.es

$\checkmark$ Institut Cartogràfic de Catalunya (ICC). http://www.cartotecadigital.icc.cat

Os arquivos virtuais são essenciais na medida que permitem acesso à informação tanto por parte de pesquisadores, como da sociedade em geral, e constituem importante fonte de dados e poderoso recurso didático-pedagógico. 


\section{GEOPROCESSAMENTO DE MAPAS HISTÓRICOS}

Nas pesquisas com mapas históricos surgem indagações sobre a autoria do mapa, a data do mapeamento, as técnicas empregadas, os desvios de projeção, o contexto político e social da elaboração do mapa, entre outros aspectos de interesse para investigações.

Uma alternativa para solucionar parte destas questões, foi a proposta de georreferenciamento e vetorização de mapas históricos desenvolvida por Castro (2011), na qual o autor contribui com um procedimento metodológico com três etapas: "inventário das fontes" - referenciamento, catalogação, etc.; "processo" - conteúdo e representação e análise de mapas e de textos; e "produto" - o georreferenciamento e o tratamento da informação espacial (Figura 1).

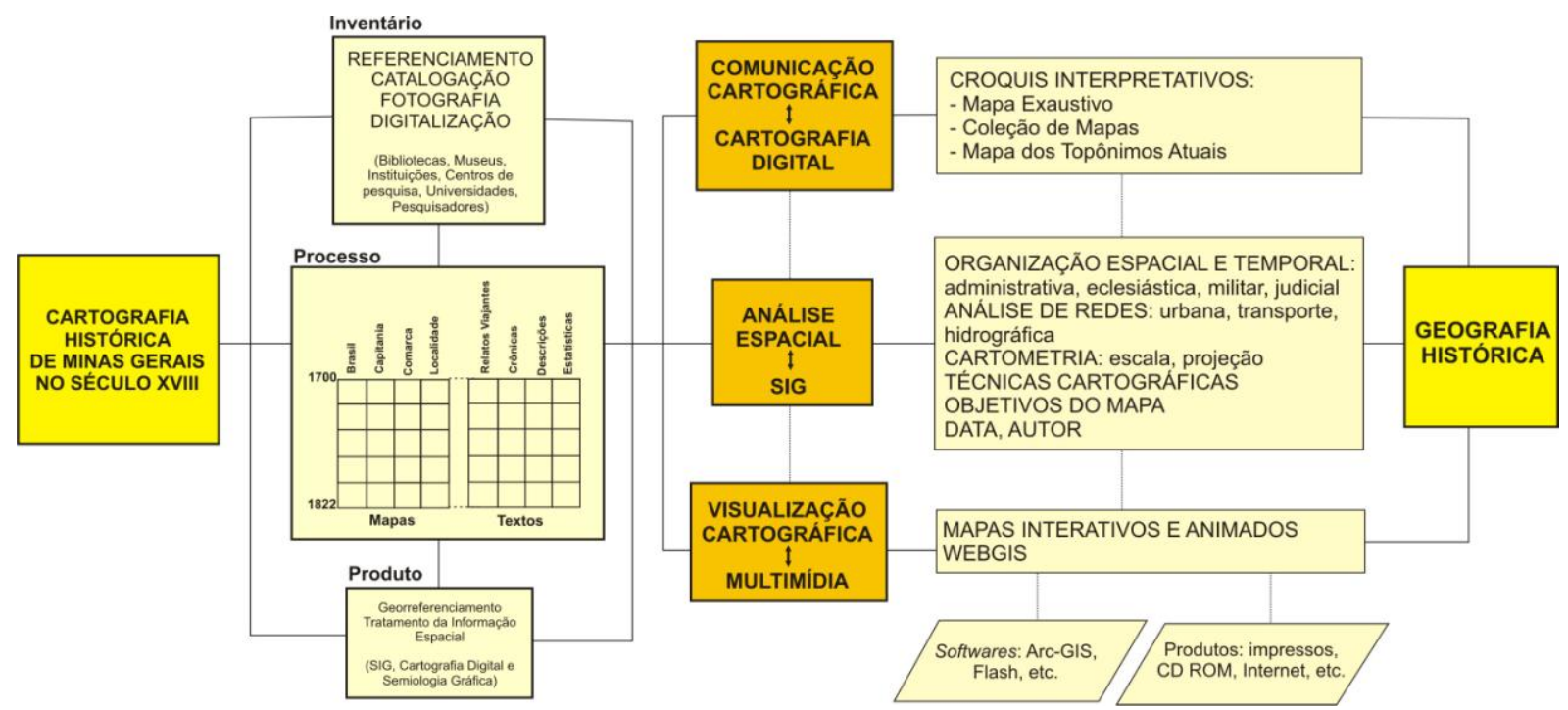

Figura 1 - Metodologia de análise de mapas históricos por geoprocessamento;

Fonte: Castro (2011).

O roteiro metodológico é fundamentado nos princípios da Cartografia analógica e da "Comunicação Cartográfica"", especialmente a "Semiologia Gráfica"³, e associa-se aos recursos técnicos da "Cartografia Digital" ${ }^{4}$ do SIG e da "Visualização Cartográfica"5 . A geração de um banco de dados digital permite a elaboração de variadas análises em mapas históricos, tais como: croquis interpretativos, mapa exaustivo, coleção de mapas, mapas

\footnotetext{
${ }^{2}$ Veja maiores detalhes sobre Comunicação Cartográfica em: Oliveira (1978); Simielli (1986); Board (1994); Kolacny (1994); Koeman (1995); Petchenik (1995); entre outros.

${ }^{3}$ Veja maiores detalhes sobre Semiologia Gráfica em: Bertin (1973 e 1988); Le Sann (1983); Martinelli (1991); entre outros.

${ }^{4}$ Veja maiores detalhes sobre Cartografia Digital em: Tobler (1959 e 1976): Cromley (1992); entre outros.

${ }^{5}$ Veja maiores detalhes sobre Visualização Cartográfica em: Maceachren (1995); Silva (2006); entre outros.
} 
temáticos, atualização de topônimos, cartométrica, redes, multimídias, entre outras aplicações.

Para aplicação de parte da metodologia proposta foi adotado, como estudo de caso, os mapas dos padres matemáticos de 1734-1735 (COSTA, 2004) e o cálculo dos "Direitos paroquiais do Bispado de Mariana" no ano de 1752, em contos de réis (BNP. Coleção Pombalina 1704/1799. Cód. 643, fl. 111-113v).

Dentre o acervo de mapas da Capitania de Minas Gerais de variadas instituições nacionais e internacionais, destacam-se os mapas dos padres matemáticos de 1734-1735 (COSTA, 2004), constituídos por 4 mapas articulados que representam a hierarquia urbana, as redes hidrográfica e viária, o alinhamento das serras e a distribuição da vegetação na região mineradora da capitania (Figura 2). Os mapas dos padres matemáticos notabilizaram-se pela precisão e pela riqueza de detalhes, em função dos avanços técnicos adquiridos, na Europa do início do século XVIII, pela astronomia, pela geodésia e pela cartografia (ALMEIDA, 2001). Referenciados ao meridiano do Rio de Janeiro, os mapas foram georreferenciados e vetorizados no $A R C \mathrm{GIS}^{\oplus}{ }^{6}$, transformados do meridiano do Rio de Janeiro para o meridiano de Greenwich, adotando-se datum SAD 69 (South America Datum 1969). Neste processo, foram gerados layers (camadas) temáticos e vetorizados os elementos: rios, estradas, vilas, paróquias, capelas, bem como, o relevo e a vegetação, adequando a simbologia à original. Em um processo de "desconstrução" do espaço cartografado e com a finalidade de minimizar os desafios de identificação e tratamento da informação mapeada, devido às dificuldades implícitas na leitura paleográfica destes documentos, por meio do uso de técnicas de geoprocessamento associadas às cartográficas, foram elaborados "mapa exaustivo" (superposição dos fenômenos em mapa único) e "coleção de mapas" (um mapa para cada fenômeno); o banco de dados digital permitiu a identificação da distribuição espacial dos fenômenos mapeados e da hierarquia urbana, adotando-se como elemento de referência as redes hidrográfica e viária, bem como, a associação dos topônimos antigos aos atuais (Figura 3).

A análise dos mapas, elaborados em escala regional, revela a organização espacial de parte da Capitania de Minas Gerais, bem como o processo de uso e ocupação do solo no início do século XVIII, fortemente influenciado pela extração do ouro; permite a identificação das

\footnotetext{
${ }^{6}$ Sistema de Informações Geográficas (SIG) licenciado para o Laboratório de Cartografia do Programa de Pós-Graduação em Geografia Tratamento da Informação Espacial (PPGG-TIE) da PUC Minas.
} 
relações entre os assentamentos urbanos, especialmente as Capelas, e a rede viária, ambos diretamente associados ao curso dos principais rios: das Velhas, Jequitinhonha e Araçuaí, caracterizando a região mineradora; permite ainda a identificação da distribuição espacial das Vilas e a concentração de Paróquias em torno de Ouro Preto, caracterizando o centro do poder administrativo e eclesiástico da capitania.

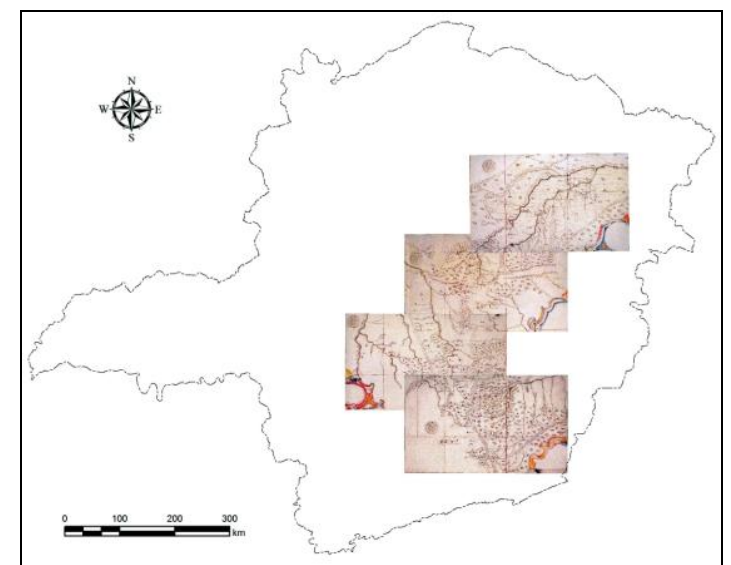

Figura 2 - Articulação dos mapas de Diogo Soares de 1734 - 1735; Fonte: Modificado de Costa (2004). 


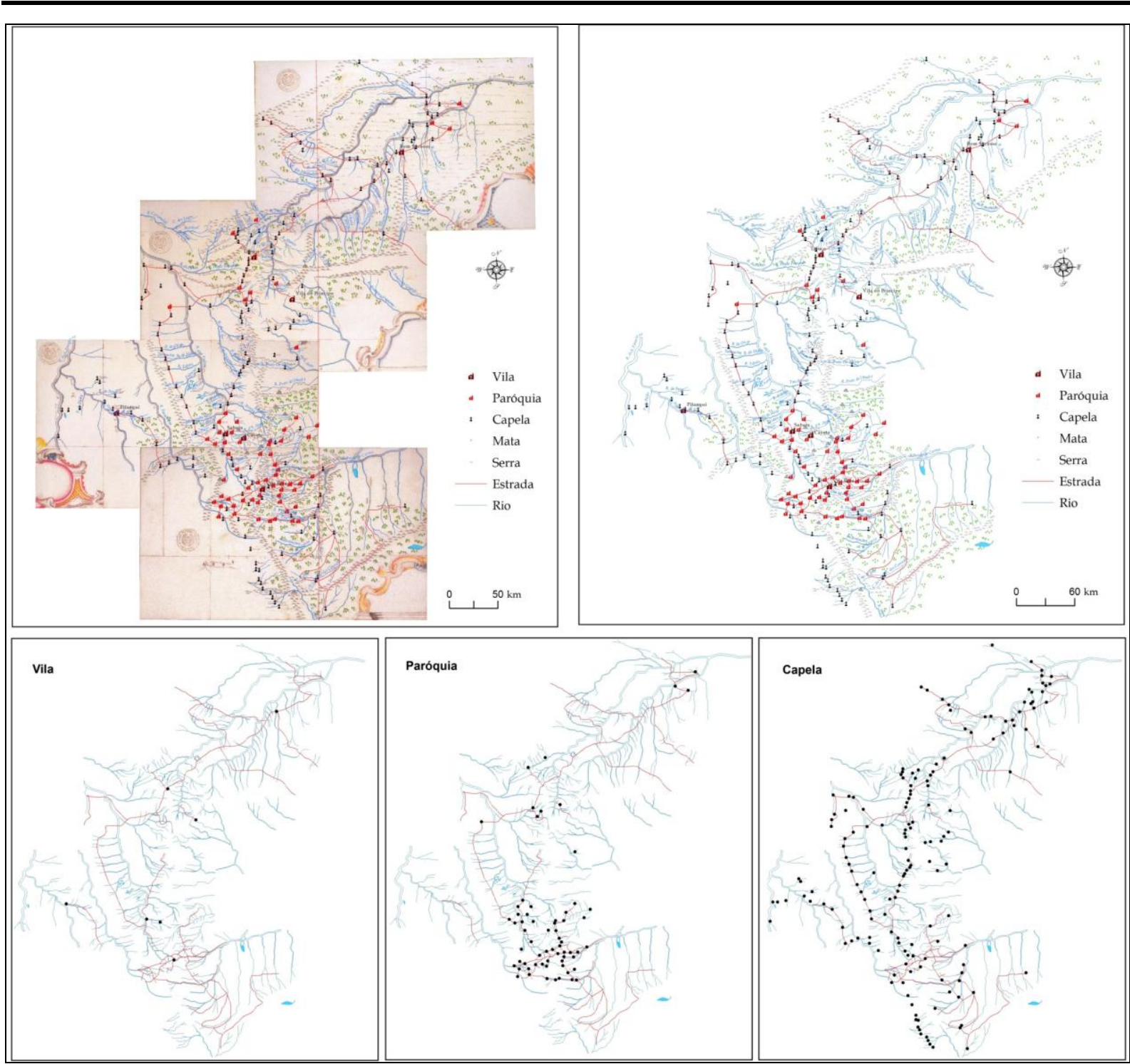

Figura 3 - Vetorização dos mapas de Diogo Soares de 1734 - 1735, representados por meio de Mapa exaustivo e Mapa de coleção destacando a hidrografia, as estradas, as vilas, as paróquias e as capelas representadas nos mapas de Diogo Soares de 1734 - 1735.

Dentre a vasta documentação da Capitania de Minas Gerais, no Brasil e em Portugal, foram levantados, nos microfilmes da Divisão dos Reservados da Biblioteca Nacional de Portugal, o cálculo dos "Direitos paroquiais do Bispado de Mariana" no ano de 1752, em contos de réis (BNP. Coleção Pombalina 1704/1799. Cód. 643, fl. 111-113v) - (Figura 4 - Quadro I).

O Bispado de Mariana foi criado pelo Papa Bento XIV, em dezembro de 1745, a partir do desmembramento do Bispado do Rio de Janeiro (BOSCHI, 2011: 13), sendo nomeado primeiro bispo Dom Frei Manuel da Cruz (1745-1764), que contava, em 1752, com 51 paróquias e freguesias (LIMA JUNIOR, 1965: 158),

Segundo Kantor (2004: 230), a criação do Bispado de Mariana demarcou um novo momento geopolítico de colonização do sertão mineiro, tanto internacionalmente como localmente; 
dessa política administrativa, eclodiram os primeiros conflitos entre as autoridades civis e religiosas, cujas fronteiras administrativas apresentavam grande fluidez econômica e social.

A historiografia do período colonial tem advertido que a sobreposição de competências não representou necessariamente uma fragilidade da soberania portuguesa no ultramar, ao contrário, a concorrência entre os poderes teria sido uma estratégia eficaz de reforço da centralização régia"; por isto, a bula que instituiu o bispado de Mariana, com extensão territorial menor do que da capitania, não definiu limites entre as dioceses (KANTOR, 2004: 230).
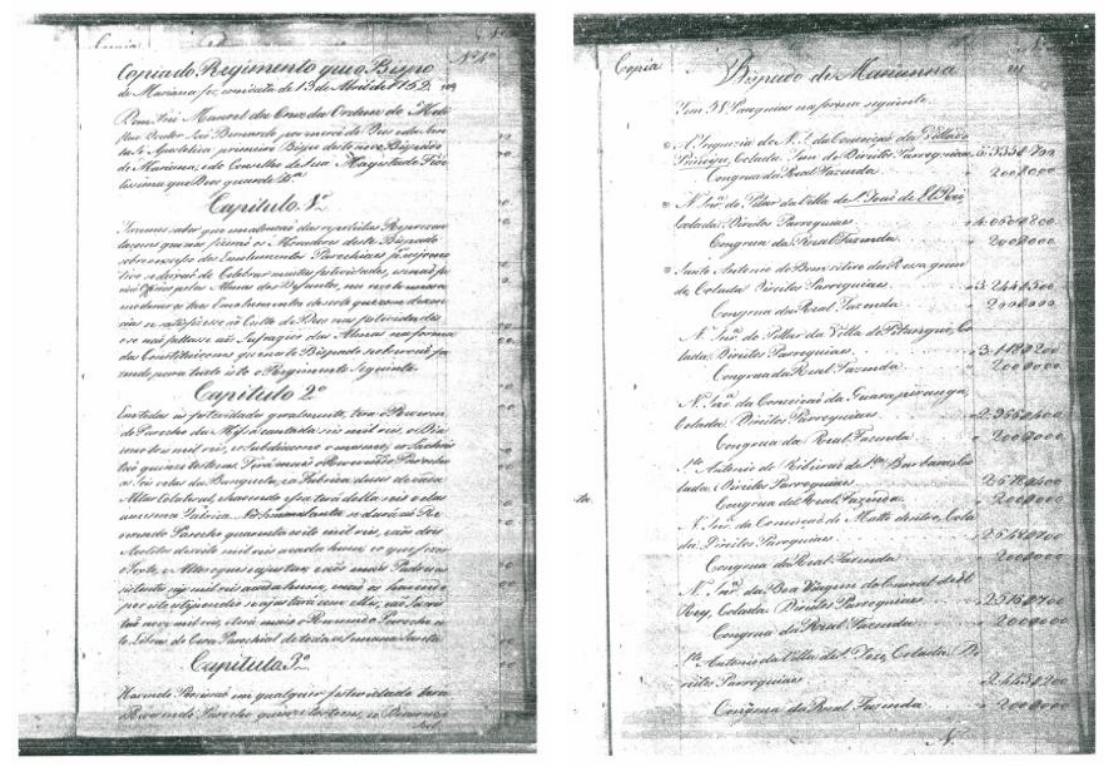

Figura 4 - Cálculo dos Direitos Paroquiais do Bispado de Mariana (1752) - em contos de réis; Fonte: BNP. Coleção Pombalina 1704/1799. Cód. 643, fl. 111-113v.

QUADRO I - Direitos paroquiais do Bispado de Mariana - 1752 (contos de réis)

\begin{tabular}{|c|c|c|c|}
\hline 1 & $\begin{array}{c}\text { Freguesia de Nossa Senhora da } \\
\text { Conceição da Aiuruoca }\end{array}$ & $1: 594 \$ 800$ & Aiuruoca \\
\hline 2 & $\begin{array}{c}\text { Nossa Senhora da Conceição de } \\
\text { Antônio Dias }\end{array}$ & $1: 660 \$ 500$ & Antônio Dias \\
\hline 3 & $\begin{array}{c}\text { Freguesia da Senhora do } \\
\text { Montserrat de Baependi }\end{array}$ & $825 \$ 300$ & Baependí \\
\hline 4 & São João Batista do Morro Grande & $996 \$ 300$ & Barão de Cocais \\
\hline 5 & $\begin{array}{c}\text { Freguesia de Nossa Senhora da } \\
\text { Piedade da Borda do Campo }\end{array}$ & $1: 873 \$ 400$ & Barbacena \\
\hline 6 & $\begin{array}{c}\text { Paróquia de São José da Barra } \\
\text { Longa }\end{array}$ & $1: 025 \$ 700$ & Barra Longa \\
\hline 7 & $\begin{array}{c}\text { Freguesia de Nossa Senhora da } \\
\text { Boa Viagem do Curral del Rei }\end{array}$ & $2: 516 \$ 700$ & Belo Horizonte \\
\hline 8 & $\begin{array}{c}\text { Nossa Senhora do Bom Sucesso da } \\
\text { Vila Nova da Rainha }\end{array}$ & $1: 492 \$ 500$ & Caeté \\
\hline 9 & Nossa Senhora da Campanha do & $1: 574 \$ 100$ & Campanha \\
\hline
\end{tabular}

\begin{tabular}{|c|c|}
\hline $1: 594 \$ 800$ & Aiuruoca \\
\hline $1: 660 \$ 500$ & Antônio Dias \\
\hline $825 \$ 300$ & Baependí \\
\hline $996 \$ 300$ & Barão de Cocais \\
\hline $1: 873 \$ 400$ & Barbacena \\
\hline $1: 025 \$ 700$ & Barra Longa \\
\hline $2: 516 \$ 700$ & Belo Horizonte \\
\hline $1: 492 \$ 500$ & Caeté \\
\hline $1: 574 \$ 100$ & Campanha \\
\hline
\end{tabular}




\begin{tabular}{|c|c|c|c|c|c|}
\hline & Rio Verde & & & & \\
\hline 10 & $\begin{array}{c}\text { Nossa Senhora da Conceição das } \\
\text { Carrancas }\end{array}$ & 1:430\$700 & Carrancas & $1: 430 \$ 700$ & Carrancas \\
\hline 11 & $\begin{array}{c}\text { Paróquia de Nossa Senhora da } \\
\text { Conceição de Catas Altas }\end{array}$ & $955 \$ 800$ & Catas Altas & $955 \$ 800$ & Catas Altas \\
\hline 12 & $\begin{array}{l}\text { Nossa Senhora da Conceição do } \\
\text { Mato Dentro } \\
\end{array}$ & $2: 648 \$ 700$ & $\begin{array}{l}\text { Conceição do } \\
\text { Mato Dentro }\end{array}$ & $2: 648 \$ 700$ & $\begin{array}{l}\text { Conceição do Mato } \\
\text { Dentro }\end{array}$ \\
\hline 13 & $\begin{array}{l}\text { Paróquia de Nossa Senhora da } \\
\text { Conceição das Congonhas }\end{array}$ & $2: 431 \$ 000$ & Congonhas & $2: 431 \$ 000$ & Congonhas \\
\hline 14 & $\begin{array}{c}\text { Nossa Senhora da Conceição dos } \\
\text { Carijós }\end{array}$ & $1: 010 \$ 100$ & $\begin{array}{c}\text { Conselheiro } \\
\text { Lafaiete }\end{array}$ & $1: 010 \$ 100$ & Conselheiro Lafaiete \\
\hline 15 & $\begin{array}{l}\text { Paróquia de Nossa Senhora da Boa } \\
\text { Viagem da Itaubira }\end{array}$ & $983 \$ 100$ & Itabirito & $983 \$ 100$ & Itabirito \\
\hline 16 & São Bento do Tamandoá & $1: 118 \$ 100$ & Itapecerica & $1: 118 \$ 100$ & Itapecerica \\
\hline 17 & Santo Antônio da Itaveraba & $1: 980 \$ 300$ & Itaverava & $1: 980 \$ 300$ & Itaverava \\
\hline 18 & $\begin{array}{c}\text { Paróquia de Nossa Senhora de } \\
\text { Nazaré do Inficionado }\end{array}$ & 1:059\$700 & Mariana & $8: 303 \$ 900$ & Mariana \\
\hline 19 & $\begin{array}{c}\text { Paróquia de Nossa Senhora do } \\
\text { Rosário do Sumidouro }\end{array}$ & 1:344\$700 & Mariana & & \\
\hline 20 & $\begin{array}{l}\text { Paróquia de Nossa Senhora da } \\
\text { Conceição de Camargo }\end{array}$ & $288 \$ 600$ & Mariana & & \\
\hline 21 & $\begin{array}{c}\text { Santo Antônio do Bom Retiro da } \\
\text { Passagem }\end{array}$ & $3: 244 \$ 500$ & Mariana & & \\
\hline 22 & Paróquia de São Sebastião & $304 \$ 800$ & Mariana & & \\
\hline 23 & $\begin{array}{l}\text { Paróquia de Nossa Senhora da } \\
\text { Conceição de Antônio Pereira }\end{array}$ & $538 \$ 800$ & Mariana & & \\
\hline 24 & Paróquia de São Caetano & $654 \$ 600$ & Mariana & & \\
\hline 25 & $\begin{array}{l}\text { Freguesia de Senhor do Bom Jesus } \\
\text { do Furquim }\end{array}$ & $868 \$ 200$ & Mariana & & \\
\hline 26 & $\begin{array}{c}\text { Freguesia de Nossa Senhora do } \\
\text { Pilar das Congonhas }\end{array}$ & $531 \$ 000$ & Nova Lima & $531 \$ 000$ & Nova Lima \\
\hline 27 & $\begin{array}{c}\text { Paróquia de Santo Antônio do } \\
\text { Ouro Branco }\end{array}$ & $493 \$ 500$ & Ouro Branco & $493 \$ 500$ & Ouro Branco \\
\hline 28 & $\begin{array}{c}\text { Paróquia de Nossa Senhora do } \\
\text { Pilar do Ouro Preto }\end{array}$ & $1: 364 \$ 100$ & Ouro Preto & $3: 120 \$ 900$ & Ouro Preto \\
\hline 29 & $\begin{array}{c}\text { Paróquia de Santo Antônio da } \\
\text { Casa Branca }\end{array}$ & $295 \$ 500$ & Ouro Preto & & \\
\hline 30 & $\begin{array}{c}\text { Paróquia de Nossa Senhora de } \\
\text { Nazaré da Cachoeira }\end{array}$ & $467 \$ 400$ & Ouro Preto & & \\
\hline 31 & Paróquia de São Bartolomeu & $492 \$ 300$ & Ouro Preto & & \\
\hline 32 & $\begin{array}{l}\text { Paróquia de Santo Antônio da } \\
\text { Itatiaia }\end{array}$ & $501 \$ 600$ & Ouro Preto & & \\
\hline 33 & $\begin{array}{c}\text { Paróquia de Nossa Senhora da } \\
\text { Conceição do Guarapiranga }\end{array}$ & $2: 966 \$ 400$ & Piranga & $2: 966 \$ 400$ & Piranga \\
\hline 34 & $\begin{array}{l}\text { Freguesia de Nossa Senhora do } \\
\text { Pilar da Vila de Pitangui }\end{array}$ & $3: 118 \$ 200$ & Pitanguí & $3: 118 \$ 200$ & Pitanguí \\
\hline 35 & $\begin{array}{c}\text { Freguesia de Nossa Senhora da } \\
\text { Conceição do Pouso Alto }\end{array}$ & $497 \$ 100$ & Pouso Alto & $497 \$ 100$ & Pouso Alto \\
\hline 36 & $\begin{array}{c}\text { Nossa Senhora da Conceição dos } \\
\text { Prados }\end{array}$ & $1: 198 \$ 200$ & Prados & $1: 198 \$ 200$ & Prados \\
\hline 37 & $\begin{array}{c}\text { Freguesia de Nossa Senhora da } \\
\text { Conceição dos Raposos }\end{array}$ & $676 \$ 800$ & Raposos & $676 \$ 800$ & Raposos \\
\hline 38 & $\begin{array}{l}\text { Freguesia de Santo Antônio do Rio } \\
\text { Acima }\end{array}$ & $742 \$ 200$ & Rio Acima & $742 \$ 200$ & Rio Acima \\
\hline 39 & Freguesia de São Miguel da & $1: 714 \$ 500$ & Rio Piracicaba & $1: 714 \$ 500$ & Rio Piracicaba \\
\hline
\end{tabular}




\begin{tabular}{|c|c|c|c|c|c|}
\hline & Piracicaba & & & & \\
\hline 40 & $\begin{array}{c}\text { Paróquia de São Manoel dos } \\
\text { Índios Coroados do Rio da Pomba }\end{array}$ & $163 \$ 600$ & Rio Pomba & $163 \$ 600$ & Rio Pomba \\
\hline 41 & $\begin{array}{c}\text { Nossa Senhora da Pena do Rio } \\
\text { Vermelho }\end{array}$ & $170 \$ 700$ & Rio Vermelho & $170 \$ 700$ & Rio Vermelho \\
\hline 42 & $\begin{array}{l}\text { Freguesia de Nossa Senhora da } \\
\text { Conceição da Vila Real de Sabará }\end{array}$ & $2: 247 \$ 300$ & Sabará & $2: 688 \$ 300$ & Sabará \\
\hline 43 & $\begin{array}{c}\text { Freguesia de Nossa Senhora da } \\
\text { Conceição do Rio das Pedras }\end{array}$ & $441 \$ 000$ & Sabará & & \\
\hline 44 & $\begin{array}{c}\text { Freguesia de Santo Antônio, } \\
\text { Ribeirão de Santa Bárbara }\end{array}$ & $2: 678 \$ 400$ & Santa Bárbara & $2: 678 \$ 400$ & Santa Bárbara \\
\hline 45 & $\begin{array}{l}\text { Freguesia de Nossa Senhora da } \\
\text { Assunção do Engenho }\end{array}$ & $122 \$ 000$ & São João del Rei & $4: 182 \$ 800$ & São João del Rei \\
\hline 46 & $\begin{array}{l}\text { Paróquia de Nossa Senhora do } \\
\text { Pilar da Vila de São João del Rei }\end{array}$ & $4: 060 \$ 800$ & São João del Rei & & \\
\hline 47 & $\begin{array}{l}\text { Freguesia de Nossa Senhora da } \\
\text { Conceição da Vila do Príncipe }\end{array}$ & $6: 335 \$ 700$ & Serro & $6: 335 \$ 700$ & Serro \\
\hline 48 & $\begin{array}{c}\text { Freguesia de Nossa Senhora da } \\
\text { Glória do Caminho Novo }\end{array}$ & $131 \$ 100$ & Simão Pereira & $131 \$ 100$ & Simão Pereira \\
\hline \multirow[t]{2}{*}{49} & Santo Antônio da Vila de São José & $2: 443 \$ 200$ & Tiradentes & $2: 443 \$ 200$ & Tiradentes \\
\hline & $\begin{array}{l}\text { TOTAL } \\
\end{array}$ & $68: 273 \$ 600$ & & & \\
\hline
\end{tabular}

* Nos municípios em negrito, os dados dos distritos foram somados com os dados da sede FONTE: BNP. Coleção Pombalina (1752). Cód. 643, fl. 111-113v.

Com o objetivo de se analisar como se processaram os direitos paroquiais na capitania, cujas localizações são apresentadas no mapa da figura 5, foi elaborado o mapa de figuras geométricas proporcionais da arrecadação, ou seja, a arrecadação é proporcional ao diâmetro da figura (Figura 6). 


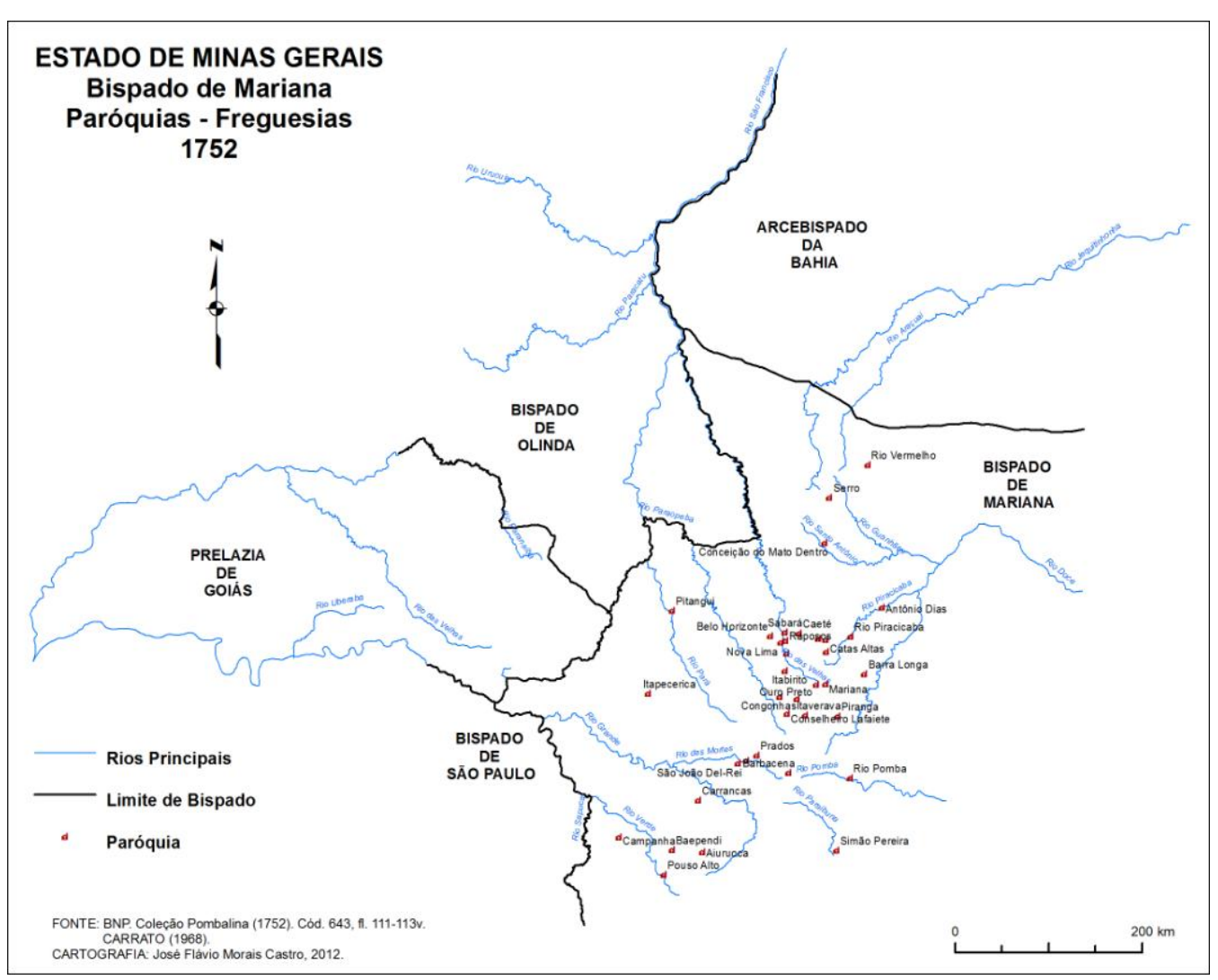

Figura 5 - Limite aproximado do bispado de Mariana e as respectivas paróquias em 1752.

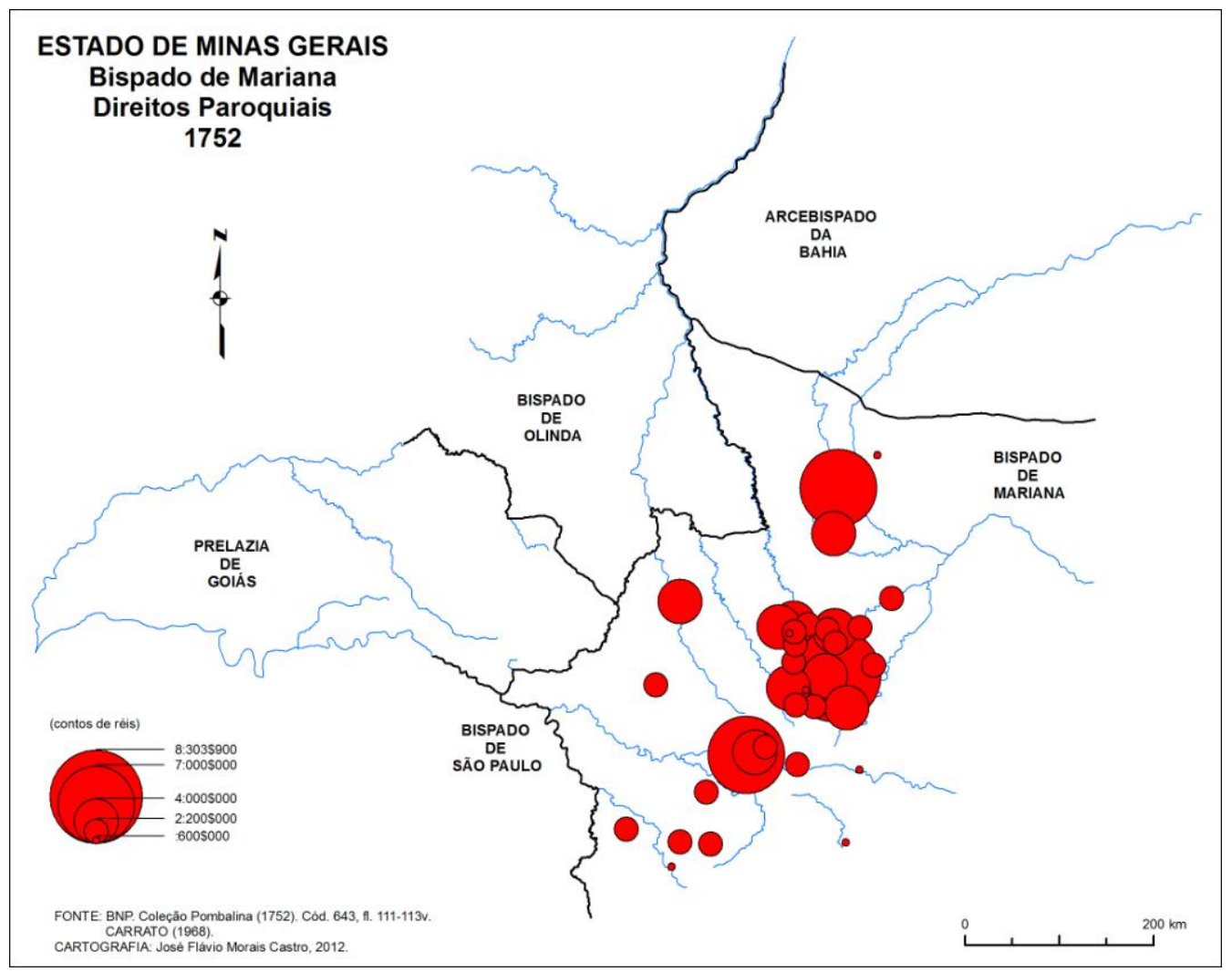

Figura 6 - Mapa dos direitos paroquiais do Bispado de Mariana em 1752. 
A análise do mapa revela a concentração de arrecadação nas paróquias de Mariana e de Vila

Rica, e entorno, seguida pelas paróquias de São João del Rei e do Serro; revela, também, a importância exercida pelas instituições eclesiásticas na economia da capitania de Minas Gerais no século XVIII.

\section{CONSIDERAÇÕES FINAIS}

O trabalho apresentado é parte integrante da Linha de Pesquisa "História da Cartografia e Cartografia Histórica" que vem sendo desenvolvida no Programa de Pós-Graduação em Geografia - Tratamento da Informação Espacial da PUC Minas. Os resultados obtidos compreendem parte do roteiro metodológico proposto e integram o banco de dados digital de mapas históricos em ambiente SIG; fundamental para futuras análises espaciais.

Com a técnica do georreferenciamento e da vetorização de mapa histórico em estrutura de layer, além de desmistificar a leitura dos mapas históricos, devida a paleografia, obtém-se produtos cartográficos que podem ser aplicados em variadas pesquisas e que podem representar importante recurso didático-pedagógico. Os mapas históricos necessitam de estudos aprofundados sobre o contexto político, econômico e social que foram produzidos, para se compreender como o poder se expressou na representação cartográfica à época e quais foram seus efeitos na sociedade.

\section{REFERÊNCIAS BIBLIOGRÁFICAS}

ÁVILA, Cristina. Hélio Gravatá: Resgate bibliográfico de Minas Gerais. Belo Horizonte: Fundação João Pinheiro, Centro de Estudos Históricos e Culturais, v. 1 e 2, 1998.

BARBOSA, W. A. Dicionário Histórico-Geográfico de Minas Gerais. $2^{\text {a }}$ ed. Belo Horizonte: Itatiaia, 1995.

ALMEIDA, A. F. A formação do espaço brasileiro e o projecto do Novo Atlas da América Portuguesa (1713-1748). Lisboa: Comissão Nacional para as Comemorações dos Descobrimentos Portugueses, 2001.

BERTIN, J. Semiologie Graphique. 2a. ed., Paris: Mouton-Gauthier-Villars, 1973.

BERTIN, J. Ver ou ler. Seleção de Textos, São Paulo, (18):45- 62, 1988.

BERRY, B. J. L.; MARBLE, D. F. (eds.) Spatial Analysis: A Reader in Statistical Geography. New Jersey: Prentice-Hall Inc., Englewood Cliffs, 1968. 
BOARD, C. A contribuição do geógrafo para a avaliação de mapas como meio de comunicação de informações. Geocartografia: Textos selecionados de cartografia teórica, Departamento de Geografia/FFLCH/USP, n. 3, 1994.

BOSCHI, Caio C. (Coord.) Fontes primárias para a História de Minas Gerais em Portugal. Belo Horizonte: Fundação João Pinheiro, Centro de Estudos Históricos e Culturais, 1998a. $124 \mathrm{p}$.

BOSCHI, Caio C. (Coord.) Inventário dos manuscritos avulsos relativos a Minas Gerais existentes no Arquivo Histórico Ultramarino (Lisboa). Belo Horizonte: Fundação João Pinheiro, Centro de Estudos Históricos e Culturais, 1998b. 3v. (Coleção Mineiriana. Série Obras de Referência).

BOSCHI, Caio C. Cabido da Sé de Mariana (1745-1820): Documentos Básicos. Belo Horizonte: Fundação João pinheiro, Editora PUC Minas, 2011.

BURROUGH, P. A. Principles of Geographical Information Systems for Land Resources Assessment. London: Clarendon Press, 1986.

CÂMARA, G.; CASANOVA, M. A.; HeMERLEY, A. S. MAGAlHÃES, G. C.; MEdeiros, C. M. B. Anatomia de Sistemas de Informações Geográficas. 10ª Escola de Computação. Campinas, UNICAMP, 1996.

CAMARGOS, L. A.; CASTRO, J.F.M. Análise cartométrica do mapa "Karte Der Brasilianische Provinz Minas Geraes" - 1862 de H.W.F Halfeld e F.Wagner. In: Anais do I Congresso Brasileiro de Organização do Espaço. Programa de Pós-Graduação em Geografia/IGCE/UNESP, Rio Claro, p. 3155-3167, 2010.

CAMARGOS, L. A. Análise semiológica, cartométrica e toponímica do Mapa da Província de Minas Gerais (1862): uma contribuição aos estudos de Cartografia Histórica e SIG. Dissertação de Mestrado. Programa de Pós-Graduação em Geografia - Tratamento da Informação Espacial da PUC Minas, Belo Horizonte, 2012.

CARVALHO, L. F.; CASTRO, J. F. M. . Geoprocessamento de mapas históricos da capitania de Minas Gerais. In: 17o. Seminário de Iniciação Científica. Iniciação Científica: destaques de 2009. Belo Horizonte: Ed. PUC Minas, 2009. p. 285-299.

CARVALHO, L. F.; CASTRO, J. F. M. Resgate de Mapas Históricos da Capitania de Minas Gerais em ambiente SIG. 3o Simpósio Iberoamericano de História da Cartografia, São Paulo, USP, p. 1-20, 2010.

CASTRO, C. A. Sertão do Alto São Francisco, Minas Gerais: uma representação da paisagem a partir dos relatos de viagem e da Cartografia do Barão de Eschwege. Dissertação de Mestrado. Programa de Pós-Graduação em Geografia - Tratamento da Informação Espacial da PUC Minas, Belo Horizonte, 2012.

CASTRO, J. F. M. Comunicação cartográfica e visualização cartográfica. Boletim Paulista de Geografia, AGB, no. 87, p. 67-83, 2007. 
CASTRO, J. F. M. Geografia Histórica e Cartografia de Minas Gerais no século XVIII. Relatório de Pesquisa de Pós-doutoramento. Porto: Faculdade de Letras da Universidade do Porto (FLUP), 2011.

CASTRO, J. F. M. Georreferenciamento e cartometria dos mapas da Capitania de Minas Gerais elaborados por José Joaquim da Rocha em 1778 e 1793. Sociedade \& Natureza (UFU. Online), v. 25, p. 581-593, 2013.

CÓDICE Costa Matoso [coleção das notícias dos primeiros descobrimentos das minas na América, que fez o doutor Caetano Costa Matoso sendo ouvidor-geral das do Ouro Preto, de que tomou posse em fevereiro de 1749 , \& vários papéis]. Belo Horizonte: Fundação João Pinheiro, Centro de Estudos Históricos e Culturais, 1999. (Coleção Mineiriana, Série Obras de referência).

CORTESÃO, Jaime. História do Brasil nos velhos mapas. Lisboa: Imprensa Nacional/Casa da Moeda, Tomo II, 2009.

COSTA, A. G.; RENGER, F. E.; FURTADO, J. F.; SANTOS, M. M. D. Cartografia de Minas Gerais: Da Capitania à Província. Belo Horizonte: Editora UFMG; Lisboa: Kapa Editorial, 2002. 84 p.

COSTA, A. G. (organização). Cartografia da Conquista do Território das Minas. Belo Horizonte: Editora UFMG; Lisboa: Kapa Editorial, 2004, 245 p.

COSTA, Antônio Gilberto (Org.). Os caminhos do ouro e a Estrada Real. Belo Horizonte: Editora da UFMG; Lisboa: Kapa Editorial, 2005.

COSTA, A. G. (organização). Roteiro Prático de Cartografia: da América portuguesa ao Brasil Império. Belo Horizonte: Editora UFMG, 2007, 255 p.

CROMLEY, R. G. Digital Cartography. New Jersey: Prentice Hall, 1992.

DAIAN, N. P. A organização espacial das atividades econômicas em Minas Gerais nos setecentos e oitocentos. Dissertação de Mestrado. Programa de Pós-Graduação em Geografia - Tratamento da Informação Espacial da PUC Minas, Belo Horizonte, 2011.

ESCHWEGE, Wilhelm Ludwig von. Pluto brasiliensis. Belo Horizonte: Itatiaia; São Paulo: Edusp, 1979.

ESCHWEGE, Wilhelm Ludwig von. Brasil, novo mundo. v. I, Belo Horizonte: Fundação João Pinheiro, Centro de Estudos Históricos e Culturais, 1996.

ESCHWEGE, Wilhelm Ludwig von. Brasil, novo mundo. v. II Belo Horizonte: Fundação João Pinheiro, Centro de Estudos Históricos e Culturais, 2000.

ESCHWEGE, Wilhelm Ludwig von. Jornal do Brasil, 1811-1817: relatos diversos do Brasil, coletados durante expedições científicas. Belo Horizonte: Fundação João Pinheiro, Centro de Estudos Históricos e Culturais, 2002. 
FERRAND, Paul. O Ouro em Minas Gerais. Tradução de Júlio C. Guimarães; notas de João H. Grossi, Friedrich E. Renger; estudos críticos J. H. Grossi et al. Belo Horizonte: Fundação João Pinheiro, Centro de Estudos Históricos e Culturais, 1998.

GOMES, Maria do Carmo Andrade. Velhos mapas, novas leituras: Revisando a História da Cartografia. GEOUSP - Espaço e Tempo, São Paulo, no 16, pp. 67-79, 2004.

HALFELD, Henrique Guilherme Fernando; TSCHUDI, Johann Jakob von: trad. Myriam Ávila; ensaio crítico, notas e revisão da tradução Roberto Borges Martins.. A província brasileira de Minas Gerais. Belo Horizonte: Fundação João Pinheiro, Centro de Estudos Históricos e Culturais, 1998.

HARLEY, J. B. Maps and the Columbian Encouter. Milwaukee: Golda Meir Library, 1990.

HARLEY, J. B. A nova história da cartografia. O Correio da Unesco, ano 19, n. 8, p. 4-10, 1991.

INSTITUTO DE GEOCIÊNCIAS APLICADAS (IGA); ASSEMBLÉIA LEGISLATIVA DO ESTADO DE MINAS GERAIS (ALEMG). As denominações urbanas de Minas Gerais: cidade e vilas mineiras com estudo toponímico e da categoria administrativa. Belo Horizonte: Assembléia Legislativa do Estado de Minas Gerais, 1993 e 1997.

JENNY, Bernhard; WEBER, Adrian; HURNI, Lorenz. Visualizing the planimetric accuracy of historical maps with MapAnalyst. Cartographica, 42, 1, p. 89-94, 2007.

KANTOR, Íris. Ritualidade pública no processo de implantação do Bispado de Mariana (Minas Gerais - 1745-1748). Proj. História, São Paulo, 28:229-242, 2004.

KOEMAN, C. O princípio da comunicação na cartografia. Geocartografia: Textos selecionados de cartografia teórica, Dep. de Geografia/FFLCH/USP, n. 5, 1995.

KOLACNY, A. Informação cartográfica: conceitos e termos fundamentais na cartografia moderna. Geocartografia: Textos selecionados de cartografia teórica, Departamento de Geografia/FFLCH/USP, n. 2, 1994.

KNOWLES, Anne Kelly (editor). Past time, past place: GIS for history. Redlands, California: ESRI Press, 2002. 202p.

LAGO, Pedro Corrêa do. Brasiliana Itaú: uma grande coleção dedicada ao Brasil. São Paulo: Capivara Editora, 2009. 708 p.

LE SANN, J. G. Documento cartográfico: considerações gerais. Revista Geografia e Ensino, Belo Horizonte, n. 1, v. 3. p. 3-17, 1983.

LIMA JÚNIOR, Augusto de. A Capitania de Minas Gerais: origens e formação. 3ạ. Ed., Belo Horizonte: Edição do Instituto de História, Letras e Arte, 1965.

MACEACHREN, A. M. How Maps Work: representation, visualization and design. New York: Guilford Press, 1995. 
MAGALHÃES, J. R. (Coord.). Lugares e Regiões em Mapas Antigos. Lisboa: Comissão Nacional para as Comemorações dos Descobrimentos Portugueses / Biblioteca Pública de Évora, 1997.

MAGUIRE, D. J.; GOODCHILD, M. F.; RHIND, D. W. (Eds.) Geographical Information Systems: Principles and Aplications. New York: Wiley, 1991.

MARQUES, M. S. Cartografia Antiga: tabela de equivalências de medidas, cálculo de escalas e conversão de valores de coordenadas geográficas. Lisboa: Biblioteca Nacional, 2001.

MARTINELLI, M. Curso de Cartografia Temática. São Paulo: Contexto, 1991.

MATOS, Raimundo José da Cunha. Corografia histórica da Provincia de Minas Gerais (1837). Belo Horizonte: Ed. Itatiaia; São Paulo: Ed. da Universidade de São Paulo, 1981.

OLIVEIRA, L. Estudo metodológico e cognitivo do mapa. Tese de Livre-Docência, IG/USP, São Paulo, 1978.

PETCHENIK, B. B. Cognição em Cartografia. Geocartografia: Textos selecionados de cartografia teórica, Departamento de Geografia/FFLCH/USP, n. 6, 1995.

ROCHA, J. J. da. Geografia histórica da Capitania de Minas Gerais. Descrição geográfica, topográfica, histórica e política da Capitania de Minas Gerais. Memória Histórica da Capitania de Minas Gerais. Estudo crítico Maria Efigênia Lage de Resende; transcrição e colação de textos Maria Efigênia e Rita de Cássia Marques. Belo Horizonte: Fundação João Pinheiro, Centro de Estudos Históricos e Culturais 1995.

SAINT-HILAIRE, Auguste de. Segunda viagem do Rio de Janeiro a Minas Gerais e São Paulo, 1822. Tradução revista e prefácio de Vivaldi Moreira. Belo Horizonte: Ed. Itatiaia; São Paulo: Ed. da Universidade de São Paulo. 1974a.

SAINT-HILAIRE, Auguste de. Viagem ao Espírito Santo e Rio Doce. Tradução de Milton Amado; prefácio de Mário Guimarães Ferri.. Belo Horizonte: Ed. Itatiaia; São Paulo: Ed. da Universidade de São Paulo. 1974b.

SAINT-HILAIRE, Auguste de. Viagem às nascentes do rio São Francisco. Tradução de Regina Regis Junqueira; prefácio de Mário Guimarães Ferri. Belo Horizonte: Ed. Itatiaia; São Paulo: Ed. da Universidade de São Paulo. 1975.

SILVA, José Joaquim da. Tratado de geografia descritiva especial da província de Minas Gerais. Introdução Oswaldo Bueno Amorim Filho; atualização ortográfica Maria Lúcia Brandão Freire de Mello. Belo Horizonte: Fundação João Pinheiro, Centro de Estudos Históricos e Culturais 1997.

SILVA, R. M. P. Visualização cartográfica e morfométrica da bacia do córrego da Mutuca município de Nova Lima / MG. Dissertação de mestrado, PPGG-TIE/ PUC Minas, Belo Horizonte, 2006. 
SILVA FILHO, E.; AMORIM FILHO, O. B.; CASTRO, J. F. M. A contextualização histórica e geográfica dos quilombos do Campo Grande. Anais do I Simpósio Brasileiro de Cartografia Histórica. Parati, 2011. (no prelo)

SILVA FILHO, E. A contextualização histórica e geográfica de mapas sobre as áreas quilombolas das Minas Gerais dos setecentos: os quilombos da região do Campo Grande. Dissertação de Mestrado. Programa de Pós-Graduação em Geografia - Tratamento da Informação Espacial da PUC Minas, Belo Horizonte, 2011.

SIMIELLI, M. E. R. O mapa como meio de comunicação: implicações no ensino da geografia do 1 o grau. Tese de Doutoramento, FFLCH/USP, São Paulo, 1986.

TOBLER, W. R. Automation and Cartography. Geographical Review, v. 49, p. 526-534, 1959.

TOBLER, W. R. Analytical Cartography. The American Cartographer, v. 3, n. 1, p. 21-31, 1976.

VASCONCELOS, Diogo de. História Antiga de Minas Gerais. Prefácio de Francisco Iglésias; introdução de Basílio de Magalhães. Belo Horizonte: Ed. Itatiaia, 1999. 